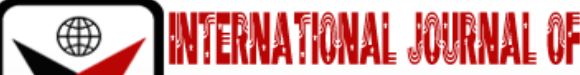

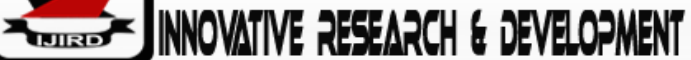

ISSN 2278-0211 (Online)

\section{Cigarette Smoking Pattern and the Effect on the Airway among University of Port Harcourt Medical Students}

Dr. Nwogbo Augustine
Senior Lecturer, Department of ENT, University of Port Harcourt Teaching Hospital, Nigeria
Dr. Peterside A.
Lecturer, Department of ENT, University of Port Harcourt Teaching Hospital, Nigeria

\begin{abstract}
:
Background

Tobacco or cigarette smoking is a habit which could cause morbidity and even immortality sometimes to the individual involved.

Some involved in the practice are sometimes ignorant of the hazards posed by the act of smoking. This study seeks to find out believes amongst medical students in a tertiary centre.

Methodology: this is a cross- sectional study of (200) two-hundred students in which questionnaires were introduced to each student for response. About (30) questions were presented and various response from these students were recorded and analysed.

Results:

200 responders were involved in the study. (144) (72\%) one hundred and forty-four male and 56 (28\%) females with male /female ration of 2:1 most smokers were within age range 20-24 (45\%). 60 (30\%) sixty of them were smokers at the time of response and 79 (39\%) were out rightly non-smokers.

Conclusion:

Medical education or education has not had drastic reduction in the habit of smoking. Friends present greater influence on the habit. Majority believe it can give rise to cancer, especially in the living.
\end{abstract}

Keywords: Cigarette smoking, airway effect, tobacco

\section{Introduction}

Tobacco has been in use in our country since our grand-fathers existed. In Europe, tobacco has been reported to be in use for less than 400 years ago. It has been smoked in pipes, cigars ad cigarettes and it has been taken as snuff. It has been praised by many and, until the last twenty years condemned by relatively few. Factory made cigarettes have come to be by far the commonness means of smoking tobacco only during the twentieth century. But during this century the production and smoking of cigarettes so greatly increase that their ill-effects have been most forcibly brought to medical and then to public notice.

The aim of this cross-sectional study is to look at cigarette smoking pattern among University of Port Harcourt Medical Students as well as what they believe about cigarette smoking. The effect on the airway and other organs. Then compare it with findings in other similar work. That cigarette smoking is a major cause of morbidity and mortality has been demonstrated so many times in so many countries that it is neither desirable nor practicable to review the evidence in detail here. In fact, it has been documented that the man who smokes twenty or more cigarettes a day from the age of twenty onwards is likely to live five years less than the non-smoker of the same age, and if he smokes forty or more, he is likely to live eight years less. The man of forty smoking twenty cigarettes a day has double the chance of dying in the next ten years than non-smokers.

\subsection{Materials and Methods}

This study is based upon the answers to 200 questionnaires filled out by cross-section of University of Port Harcourt Medical Students only, within the month of January 2018 Pre-degree (Year 1) Medical Students were not included in this study.

The questionnaires contained 30 questions all framed towards finding out cigarette smoking pattern of each student. Both males and females of each class were involved in this study. Each student was allowed to take the questionnaires to his/her room and to return it after completion. Completed questionnaires were later assembled and analysed. 


\section{Results}

\begin{tabular}{|c|c|c|}
\hline Age & Number & Percentage \\
\hline 15 and below & - & 18.5 \\
\hline $15-19$ & 37 & 45 \\
\hline $20-24$ & 90 & 26.5 \\
\hline $25-29$ & 53 & 10 \\
\hline $30-34$ & 20 & - \\
\hline $35-39$ & - & - \\
\hline $40-44$ & - & - \\
\hline $45-49$ & - & - \\
\hline $50-54$ & - & - \\
\hline Total & 200 & \\
\hline
\end{tabular}

Table 1: Age Group of Respondents, Showing the Highest Number within Age Group of 20-24

\begin{tabular}{|c|c|c|}
\hline Male & Female & Total \\
\hline $144(72 \%)$ & $56(28 \%)$ & 200 \\
\hline
\end{tabular}

Table 2: Shows the Gender of Number of Students Interviewed

\begin{tabular}{|c|c|c|c|}
\hline Marital Status & Male & Female & Number \\
\hline Married & 8 & 2 & $10(5 \%)$ \\
Single & 136 & 54 & $190(95 \%)$ \\
Divorced & & & - \\
Separated & & & - \\
Widowed & & 56 & - \\
\hline Total & 144 & & 200 \\
\hline
\end{tabular}

Table 3: Shows The Marital Status of Students Interviewed. Only 10 Are Married, with Male to Female Ration as 4:1

\begin{tabular}{|c|c|}
\hline Religious & Number \\
\hline Christianity & $185(92.5 \%)$ \\
Islam & $8(4 \%)$ \\
Hindu & $1(0.5 \%)$ \\
Free Thinkers & $3(1.5 \%)$ \\
Traditional & $3(1.5 \%)$ \\
\hline Total & $200 \%$ \\
\hline
\end{tabular}

Table 4: Shows the Religious Believe of a Students, Three, Described Themselves as Free Thinkers

\begin{tabular}{|c|c|}
\hline Free & Number \\
\hline 11 & $185(92.5 \%)$ \\
111 & $8(4 \%)$ \\
$1 \mathrm{~V}$ & $1(0.5 \%)$ \\
$\mathrm{V}$ & $3(1.5 \%)$ \\
$\mathrm{V} 1$ & $3(1.5 \%)$ \\
Did not indicate class & $7(3.5 \%)$ \\
Total & $200 \%$ \\
\hline
\end{tabular}

Table 5: Represents the Number of Students Interviewed in Each Class

Table 5 represents the number of students interviewed in each class. Year 1 (pre-degree) students were not included in this study, while seven students did not indicate their class.

\begin{tabular}{|c|c|c|c|}
\hline Pattern of Smoking & Total Number & Male & Female \\
\hline Presently Smoking & $60(30 \%)$ & $4166 \% 60$ & - \\
Had Smoked but quit & $61(30.5)$ & $41(28.4)$ & $20(35.7)$ \\
Has never smoked before & $79(39.5)$ & $43(29.86)$ & $36(64.28)$ \\
\hline Total & 200 & 144 & 56 \\
\hline
\end{tabular}

Table 6: Shows Overall Picture of Cigarette Smoking Pattern among Students Interviewed, with Male/Female Comparison 


\begin{tabular}{|c|c|c|}
\hline Company & Male & Female \\
\hline Brother & - & - \\
Sister & - & - \\
Mother & - & - \\
Father & - & - \\
Alone & $22(21.8)$ & - \\
Can't tell & $11(10.9)$ & 20 \\
\hline Friends & $68(67.3)$ & 20 \\
\hline Total & 101 & . \\
\hline
\end{tabular}

Table 7: Represents Company of Respondents during First Attempt of Cigarette Smoking

\begin{tabular}{|c|c|c|}
\hline Present Attitude & Male & Female \\
\hline Bother parents approve smoking & - & - \\
Both mother and father are against & 120 & 2 \\
Feels that neither cares & 8 & 54 \\
Feels he/she does not know & 16 & 56 \\
\hline Total & 144 & \\
\hline
\end{tabular}

Table 8: Shows Respondents Evaluation of the Parents' Attitude toward His /Her Smoking

\begin{tabular}{|c|c|c|}
\hline Smoking Habit of Parents & Male & Female \\
\hline Father only smoke & 16 & 1 \\
Mother only smoke & 1 & - \\
Both parents smoke & 1 & 51 \\
Neither parents smoke & 126 & 56 \\
\hline Total & 144 & \\
\hline
\end{tabular}

Table 9: Represents Smoking Habits of Parents. Only Few Parents Are Smokers, Especially Fathers

\begin{tabular}{|c|c|c|}
\hline Place & Male & Female \\
\hline Home & $28(27.7)$ & $5(25 \%)$ \\
Friend's House & $4(3.96)$ & $3(2.97)$ \\
Secondary School & $32(31.68)$ & $4(3.96)$ \\
University & $23(22.7)$ & $8(40.0)$ \\
Can't Tell & $10(9.9)$ & - \\
\hline Other secret place & $4(3.96)$ & - \\
\hline Total & 101 & 20 \\
\hline
\end{tabular}

Table 10: Shows Where Cigarette Smoking Took Place for the First Time, for Those Who Have Smoked Before, as Well as Those Presently Smoking

\begin{tabular}{|c|c|c|}
\hline Pattern of Hemp/Cigar smoking & Male & Female \\
\hline Had taken Hemp before & $10(7)$ & - \\
Had taken Cigar before & $41(28)$ & $27(48)$ \\
Not taken Hemp before & $53(38)$ & $27(48)$ \\
\hline Not taken Cigar before & $40(27)$ & \\
\hline
\end{tabular}

Table 11: Represents The Pattern of Indian hemp and Cigar Smoking among Students Interviewed. However, None Accepted Smoking Either of Them Presently, Though Some Accepted Taken Either or Both Before

\begin{tabular}{|c|c|c|c|c|c|c|c|}
\hline \multirow[b]{2}{*}{ Year } & \multirow[b]{2}{*}{ No. } & \multicolumn{2}{|c|}{ Smokers } & \multicolumn{2}{|c|}{ Non- Smokers } & \multicolumn{2}{|c|}{ Ex-Smokers } \\
\hline & & $\mathbf{M}$ & $\mathbf{F}$ & $\mathbf{M}$ & $\mathbf{F}$ & $\mathbf{M}$ & $\mathbf{F}$ \\
\hline 11 & 32 & $6 /(10)$ & - & $6(3.9)$ & $5(13.8)$ & $9(21.9)$ & $3(15)$ \\
\hline 111 & 38 & $3(5)$ & - & $6(13.9)$ & $14(38.9)$ & 8 (19.5) & $5(25)$ \\
\hline $1 \mathrm{~V}$ & 40 & $13(21.6)$ & - & $11(25.5)$ & $5(13.9)$ & $5(12.1)$ & $7(35)$ \\
\hline$V$ & 29 & $12(20)$ & - & $11(25.5)$ & $3(8.3)$ & $8(19.5)$ & - \\
\hline$V 1$ & 44 & $19(31.6)$ & - & $9(212)$ & $6(16.7)$ & $9(21.9)$ & - \\
\hline $\begin{array}{c}\text { Not } \\
\text { Indicated }\end{array}$ & 17 & 7 (11.8) & - & & $3(8.3)$ & 2. (4.8) & $5(25)$ \\
\hline Total & 200 & 60 & & 43 & 36 & 41 & 20 \\
\hline
\end{tabular}

Table 12: Represents Values of Smokers, Non-Smokers and Ex-Smokers in Each of the Classes Considered, as Well as Male/Female Relationship in Each Class 


\begin{tabular}{|c|c|c|}
\hline Chief Reasons & Male & Female \\
\hline It will harm me & $33(39.2)$ & $30(53.5)$ \\
It doesn't look good & $9(10.7)$ & $13(23.3)$ \\
I don't want to get the habit & $24(28.6)$ & $2 .(3.6)$ \\
It's too expensive & - & - \\
I don't get any enjoyment out of it, & $18(21.42)$ & $11(19.6)$ \\
It's a challenge to show others I don't & - & - \\
\hline Total & 84 & 56 \\
\hline
\end{tabular}

Table 13: Shows Reasons Given by Students about Their Not Smoking,

These Include Ex-Smokers and Those Who Have Never Smoked

\begin{tabular}{|c|c|c|}
\hline Believe Smoking Is Harmful to Health & Male & Female \\
\hline Smokers & 26 & - \\
Smoked but quit & 61 & 12 \\
Non-smokers & 44 & 24 \\
\hline No opinion on whether it causes disease & 131 & 36 \\
\hline Smokers & 1 & - \\
Smoked but quit & 3 & 8 \\
Non-smokers & 1 & 2 \\
\hline Believe it is not Harmful to health & 5 & 10 \\
\hline Smokers & 5 & - \\
Smoked but quit & 3 & - \\
Non-smokers & - & 10 \\
\hline Total & 144 & 56 \\
\hline
\end{tabular}

Table 14: Represent Respondent Believe on Whether Cigarette Has Harmful Effect on Health or Not, Some However, Did Not Give Any Response on This Issue

(Five Male and Ten Females Fall into This Category)

\begin{tabular}{|c|c|c|}
\hline Smoke Because & Male & Female \\
\hline I enjoy it & $15(25 \%)$ & - \\
Smoking relaxes me & $14(23.3)$ & - \\
It has become a habit & $9(15 \%)$ & - \\
I want to be part of the crowd & $18(30 \%)$ & - \\
It helps me defy or disobey adults & - & - \\
It helps me feel grown up & - & - \\
It helps me show off & $5(8.33)$ & \\
\hline Total & 60 & \\
\hline
\end{tabular}

Table 15: Represents Various Reasons Given by Those Presently Smoking for Doing So, Those Who Smoked, But Quit Are Excluded in This Table, Because They Did Not Respond to This Aspect of the Questionnaire

\begin{tabular}{|c|c|c|c|c|c|}
\hline \multicolumn{6}{|c|}{ Parents Smoking Habits } \\
\hline & & \multicolumn{2}{|c|}{ Smokers } & \multicolumn{2}{|c|}{ Non-smokers } \\
\hline & & $\mathbf{M}$ & $\mathbf{F}$ & $\mathbf{M}$ & $\mathbf{F}$ \\
\hline Bother parents smoke & 1 & $(0.99)$ & - & - & - \\
\hline Father only & 11 & (10.9) & - & $5(11.6)$ & 4 (11.1) \\
\hline Mother only & 1 & $(0.99)$ & - & - & $1(2.77)$ \\
\hline Neither smoke & 88 & (87.1) & $20(100)$ & $38(88.3)$ & 31 (86.1) \\
\hline Total & 101 & & 20 & 43 & 36 \\
\hline
\end{tabular}

Table 16: Represents Smoking Habit of Students Related to Smoking Habit of Parents,

Only Ex-Smokers and Those Presently Smoking Are Represented on This Table

\begin{tabular}{|c|c|c|}
\hline Other Young People Smoke Because & Male & Female \\
\hline They enjoy it & 13 & 6 \\
Smoking relaxes them & 4 & 3 \\
It has become a habit & 48 & 3 \\
They want to be part of the crowd & 42 & 38 \\
it helps them feel grown up & 14 & 6 \\
It helps them defy or disobey adults & - & - \\
It helps them show off & 23 & 56 \\
\hline Total & 144 & - \\
\hline
\end{tabular}

Table 17: Represents Reasons Given Why Other Young People Smoke, These Opinions Were Got from Both Smokers and Non-Smokers 


\section{Believe of Effect at the Airway and other Organs}

\begin{tabular}{|c|c|}
\hline No of Students & Effect on the Airway and Other Organ \\
\hline 10 & Allergic Reaction \\
10 & Inflammation \\
60 & Cancer of Larynx \\
80 & Cancer of the Lungs \\
20 & Cancer of the Pharynx \\
\hline 20 & Heart Disease \\
\hline
\end{tabular}

Table 18: Represents Response on the Effect of Cigarette Smoking on the Airway and Other Organs

\section{Discussion}

The present analysis of smoking pattern among University of Port Harcourt Medical Students shows that ninety (45\%) fall within the age group of 20-24 years, followed by 53 (26.5\%) within age of $25-29$ years. This periods fall within adolescence ages when parental control is no longer there and much of the habits acquired by the individual depend mainly on the peer group. Most implicated peer group which has influence to a large extent the smoking habit of the group under study is friends (Bynner 1969, and Levitt and Edwards 1970). Studies of adolescent smoking have demonstrated that where both parents smoke the children are more likely to smoke (Cartwright and Thomson, 1960, Salber and Macmahon, 1961). However, no strong evidence was seen in this study to support above finding. This is because from table XV1 of this present study only $11(10.9 \%)$ out of $101(70 \%)$ who are smokers or had smoked before accepted that their father smokes. One $(0.99 \%)$ accepted that both parents smoke, while same number indicated that their mother only smokes. Eighty-eight (87.1\%) were of the opinion that neither parents smoke. This observation must have resulted from parent's attitude toward smoking as seen in table V111. A hundred and seventy four, out of two hundred interviewed accepted that both parents were against smoking. Sixteen had no idea whether their parents were against cigarette smoking Table X shows were cigarette smoking took place for the first time. 32 (22.7\%) smoked first time. In the University. These are places where close association with friends is high, thereby supporting the observation that peer groups had a lot of influence of smoking habit of adolescents. Other secret places 4 (3.96\%) were variously described as 'Up a Tree'. 'In a Field', and coming home from school from table $1 \mathrm{~V} 185$ (92.5\%) out of 200 interviewed are Christians while $8(4 \%)$ are Muslims. Religious inclination did not therefore have any reduction in cigarette smoking habit of these students.

Non-smokers were asked to check the single reason which influenced them most (a) against taking up smoking (60 $(41.6 \%)$ or (b) for quitting the habit if they had been smokers 4 (28.4). after analysis of results, it appears that fear of having diseases like lung cancer, heart disease, peptic ulcer, caner of urinary bladder and other host infestations, and the wishes of their parents were the most important incentives against smoking, while religious conviction and esthetic considerations were of minor importance (Tables X111, X1V and V111). most of those who gave up smoking had been light smokers while relatively fewer were moderate or heavy smokers. On the other hand table XV represent various reasons given by those presently smoking for doing so, 18 (30\%) said they want to be part of the crowd, 15 (25\%) were of the opinion that they enjoy smoking while 14 (23.3\%) smoke because they believe that it relaxes them, $9(15 \%)$ said it has become a habit. When asked why they thought people of their own age did or did not smoke, 48 out of the 144 males interviewed said it has become a habit, 42 said they want to be part of the crowd, while 13 said they enjoy it. 38 females were of the opinion that they want to be part of the crowd. These findings which are represented on table XV11 agree with the work done by Beulah, Bewley, Blang and Harisis.

Table X1 reveals another interesting fact about smoking in these group of students. 10 (79\%) Males had taken Indian hemp before, 41 (28\%) had taken cigar at one time or the other, while 53 38\% have never taken Indian hemp before. Only $2(4 \%)$ of the females had taken cigar before. None of the female had taken Indian hem before. None accepted taking cigar or Indian hemp presently. Although there was no evidence on the questionnaires to suggest that some are presently smoking cigar or Indian hemp, it is possible that few may still be taking either cigar or hemp or both. Out of 200 students interviewed, only 10 are married, therefore there is no evidence to suggest that marital statutes any influence on cigarette smoking pattern of these students. From table V1, it is obvious that more males than females smoke. This is so probably because of two reason, one reason being that the norms of the society do not allow females to smoke, secondly more males than female were interviewed. Table $\mathrm{x}$ also gives enough evidence that apart of from friends influencing habits of cigarette smoking, place of first cigarette smoking in the secondary school, followed by home and University. The reason for this being that it is in these places that peer groups (especially friends) concentrate more.

However, apart from relationship between smoking habits and friendship plus knowledge about its hazards, some smokers would continue the habit, partly because of dependence but also by their ability to persuade themselves that their behaviour is not inconsistent with their knowledge.

Both student's knowledge and degree of conviction about the evidence were related to their stage of education, whereas their assessment of the risk was related to their own smoking behaviour, smokers being less likely to think there is a major risk, thus reducing their cognitive dissonance (Festinger, 1957). If it is accepted that, in view of the association between smoking and illness, doctors should be non-smokers, then clearly medical students need to be discouraged from the habit.

The effect of Tobacco the Airway has been widely noted in those medical literature majority of the respondents in this study believe that he lung carries greater risk. Lung cancer was accepted by many (\%) as greatest risk. 


\section{Conclusion}

In conclusion, education does not completely determine smoking habit. The influence of friends and associations may be a greater factor on an individual. Cancer has been accepted as a major risk disease, especially the lungs, followed by other organs like the larynx and the heart.

\section{References}

i. Saul R. Kelson, James L. Pullella, Anders Otterland, smoking habits and attitude among students 1964 and 1971. American Journal of Public Health September 1975 Volume 65 No. 9 pages 923- 938

ii. John H. Arnett, Maurice W. Black, Samuel S. Macnerry, cigarette smoking habits of students. American Journal of public health February 1974 Volume 64 No. pages 120-123.

iii. Temple Harrup, Bruce H. Hansen, And Krikor Soghikian, clinical methods in smoking cessation: Description and Evaluation of a stop smoking clinic. American Journal of public health December 1979 Volume 69, No.12 pages 1226-1231.

iv. Beulah R. Bewley, J.M. Bland and R. Harris. Factor associated with the starting of cigarette smoking by primary school children. British journal of preventive and social medicine February 1974 Volume 20 No. 1 pages 37-43.

v. Andrea Knopf and John Wakefield. Effect of Medical education on smoking behaviour. British journal of preventive and social medicine November 1974 Volume 28 No. 4 pages $246-251$.

vi. Julian Peto. Price and Consumption of cigarettes. Alase for intervention? British Journal of preventive and social medicine. November 1974 Volume 28 No. 4 pages 241-245.

vii. Ashford J.R. Smoking and the use of the health services. British Journal of preventive and social medicine February 1973 Volume 27 No. 1 pages 8 -17.

viii. Russell M.A.H. Changes in cigarette price and consumption by men in Britain, 1946 -197: a preliminary analysis. British Journal of preventive and social medicine. February 1973 volume 27 No. 1 pages 1-7.

ix. Sir George Godber, the case against smoking. Royal society of Health Journal. September/ October 1970. Volume 90/5 Alternative months, pages 267-269.

x. Sir Richard Dok. Smoking and Disease: Prospects for control. Royal society of Health Journal. August 1977. Volume 97 No. 4 Alternative months. Pages 167-176.

xi. Michael D. Lebowitz. Smoking Habits and changes in smoking habits as they relate to chronic conditions and respiratory symptoms. American Journal of Epidemiology 1977. Volume 105 No.6. pages 534-543.

xii. Bard S.M. AND Peacock J.B. Smoking and Drinking Habits of students at the University of Hong Kong: A longitudinal study. Public health, volume 96 No. 1 January 1982. Pages 219-225.

xiii. Charles N. Brown and Alexander D.G. Gunn. Tobacco smoking in a University Community. Public health, volume 89 No. 5 July 1975. Pages 119-205.

xiv. Petor, LopezAD, Boreham J. Thurn M.C Jr. mortality from Tobacco in developed countries. Indirect estimation from national vital statistic. Lancet 1992; 126878. 